\title{
Arbeidsmarktprognoses Regio Zwolle 2017-2022
}

Citation for published version (APA):

Peeters, T., \& Cörvers, F. (2018). Arbeidsmarktprognoses Regio Zwolle 2017-2022. ROA. ROA Fact Sheets No. 008A https://doi.org/10.26481/umarof.2018008A

Document status and date:

Published: 01/01/2018

DOI:

10.26481/umarof.2018008A

Document Version:

Publisher's PDF, also known as Version of record

\section{Please check the document version of this publication:}

- A submitted manuscript is the version of the article upon submission and before peer-review. There can be important differences between the submitted version and the official published version of record.

People interested in the research are advised to contact the author for the final version of the publication, or visit the DOI to the publisher's website.

- The final author version and the galley proof are versions of the publication after peer review.

- The final published version features the final layout of the paper including the volume, issue and page numbers.

Link to publication

\footnotetext{
General rights rights.

- You may freely distribute the URL identifying the publication in the public portal. please follow below link for the End User Agreement:

www.umlib.nl/taverne-license

Take down policy

If you believe that this document breaches copyright please contact us at:

repository@maastrichtuniversity.nl

providing details and we will investigate your claim.
}

Copyright and moral rights for the publications made accessible in the public portal are retained by the authors and/or other copyright owners and it is a condition of accessing publications that users recognise and abide by the legal requirements associated with these

- Users may download and print one copy of any publication from the public portal for the purpose of private study or research.

- You may not further distribute the material or use it for any profit-making activity or commercial gain

If the publication is distributed under the terms of Article $25 \mathrm{fa}$ of the Dutch Copyright Act, indicated by the "Taverne" license above, 


\section{Arbeidsmarktprognoses Regio Zwolle 2017-2022}

Tim Peeters

Frank Cörvers

\section{ROA Fact Sheet}

ROA-F-2018/8A

Researchcentrum voor Onderwijs en Arbeidsmarkt | ROA Research Centre For Education and the Labour Market / ROA 


\section{Arbeidsmarktprognoses Regio Zwolle 2017-2022}

\author{
Inleiding
}

Als onderdeel van het Project Onderwijs-Arbeidsmarkt (POA) stelt het ROA sinds 2013 tweejaarlijkse regionale arbeidsmarktprognoses op die tegemoet komen aan de toenemende belangstelling voor regionale arbeidsmarktinformatie. Binnen dit kader past ook voorliggende factsheet met arbeidsmarktprognoses voor de arbeidsmarktregio Regio Zwolle. Deze prognoses bestrijken de periode 2017-2022 en worden weergegeven voor 24 opleidingscategorieën die verdeeld zijn over zes opleidingsniveaus. Waar mogelijk worden de prognoses vergeleken met deze voor Overijssel als geheel, en wordt eveneens een relatie gelegd met zowel de sector- als opleidingsspecialisatie van de werkgelegenheid in de verschillende regio's. $\mathrm{Zie}$ ook Tekstbox I voor definities van de in deze factsheet gebruikte variabelen.

\section{Prognoses en actuele arbeidsmarktcijfers naar} opleidingsniveau

Zoals blijkt uit de prognoses naar opleidingsniveau in Tabel I, zijn de arbeidsmarktperspectieven voor schoolverlaters en werkzoekenden in de arbeidsmarktregio Regio Zwolle doorgaans beter dan in Overijssel als geheel. Alle opleidingsniveaus hebben namelijk een kleinere ITA, en over alle opleidingsniveaus heen wordt met een ITA van 0,99 een licht vraagoverschot verwacht. Bovendien is voor alle opleidingsniveaus de werkloosheid gemiddeld lager en de werkzaamheid hoger dan in Overijssel. Opvallend is wel dat wo-schoolverlaters aanzienlijk vaker in deeltijd werken dan in de twee andere arbeidsmarktregio's.

Voor schoolverlaters van het basisonderwijs/vmbo, hbo en wo worden goede arbeidsmarktperspectieven voorzien. In vergelijking met de andere twee arbeidsmarktregio's zijn de ITA's voor havo/vwo- en mbo 2/3-gediplomeerden ook iets gunstiger. Bij beiden komt dat vooral voort uit de aanzienlijk hogere uitbreidingsvraag (van gemiddeld I,O\% per jaar). Regio Zwolle is daarnaast de enige arbeidsmarktregio waarvoor een vraagoverschot naar hbo-afgestudeerden wordt verwacht, voornamelijk als gevolg van de relatief lage instroom van schoolverlaters. Ook schoolverlaters en werkzoekenden van het wo hebben de beste vooruitzichten in deze arbeidsmarktregio, als gevolg van een erg hoge vervangingsvraag $(4,8 \%)$.

I Voor de arbeidsmarktontwikkelingen van de hele provincie Overijssel, zie de factsheet met nummer ROA-F-2018/8.
Opvallend is dat de verwachte ITA voor basisonderwijs en vmbo (0,9I) bijna even gunstig is als deze voor wo $(0,90)$. Beide opleidingsniveaus kennen een relatief grote vervangingsvraag, maar de arbeidsmarktinstroom vanuit het basisonderwijs of vmbo (veelal voortijdig schoolverlaters van vmbo, mbo of havo/vwo) is aanzienlijk kleiner. Deze gunstige perspectieven dienen echter met enige voorzichtigheid geïnterpreteerd te worden. Een aanzienlijk deel van de vraag naar personen met basisonderwijs of vmbo als opleidingsachtergrond heeft namelijk betrekking op kleine banen. Dit kan afgeleid worden van het relatief lage gemiddeld aantal gewerkte uren per week $(26,2)$ en het hoge aandeel van studenten en scholieren (22\%). Bovendien gaat het vaak om flexibele banen met weinig doorgroeimogelijkheden. Enerzijds blijkt dit uit het lage percentage dat voltijds en vast in dienst is. Anderzijds komt dit ook tot uiting in het slechte loopbaanperspectief. De variabele "typering loopbaan", die per opleidingsniveau de loongroei tussen ca. 25 en 45 jaar (berekend voor Nederland als geheel) weergeeft in 20I6, is namelijk het minst gunstig voor laagopgeleiden, en het meest gunstig voor havo/vwo. ${ }^{2}$ Deze laatste groep bestaat mogelijk deels uit mensen die geen hogere opleiding hebben afgemaakt omdat ze door hun persoonlijke capaciteiten uitstekende kansen op de arbeidsmarkt hadden.

Verder is van belang dat de groep van laagopgeleiden met basisonderwijs of vmbo heel heterogeen is: niet alleen scholieren, maar ook voortijdig schoolverlaters zonder startkwalificatie (minimaal mbo 2 of havo), schoolverlaters van het speciaal onderwijs en arbeidsgehandicapten. Bij het aangegeven goede arbeidsmarktperspectief is geen rekening gehouden met de mogelijke sociale, fysieke en cognitieve beperkingen van mensen binnen deze groep.

\section{Sectorspecialisatie}

Uit Figuur I, die de sectorspecialisatie van Regio Zwolle toont, komt duidelijk naar voren dat deze arbeidsmarktregio gespecialiseerd is in de sector landbouw, bosbouw en visserij. Een vergelijking met de andere arbeidsmarktregio's toont bovendien dat deze arbeidsmarktregio de drijvende kracht is achter de Overijsselse specialisatie in die sector. Daarnaast is ook de Overijsselse focus op industrie deels van toepassing op Regio Zwolle, maar net zoals bij Stedendriehoek en Noordwest Veluwe (zie de betreffende

2 De indicator voor loopbaanperspectief wordt berekend aan de hand van het verschil in bruto uurloon van werkenden in de leeftijdsgroep 20-29 jaar en 40-49 jaar. Voor een argumentatie, zie Fouarge, D., Kriechel, B., \& Dohmen, T. (20I4), Occupational sorting of school graduates: The role of economic preferences, Journal of Economic Behavior \& Organization, 106, 335-351. 
Tabel 1

Arbeidsmarktprognoses (2017-2022) en actuele arbeidsmarktcijfers (2015-2016) Regio Zwolle naar opleidingsniveau

\begin{tabular}{|c|c|c|c|c|c|c|c|}
\hline & bo/vmbo & havo/vwo & $m b o 2 / 3$ & mbo 4 & hbo & wo & totaal \\
\hline \multicolumn{8}{|l|}{ Prognoses } \\
\hline Uitbreidingsvraag (\%) & 0,8 & 1,0 & 1,0 & 0,8 & 0,7 & 1,3 & 0,9 \\
\hline Vervangingsvraag (\%) & 3,7 & 2,1 & 2,6 & 1,8 & 3,0 & 4,8 & 3,0 \\
\hline Arbeidsmarktinstroom (\%) & 1,8 & 1,9 & 4,2 & 3,3 & 3,2 & 3,3 & 3,0 \\
\hline ITA & 0,91 & 1,02 & 1,08 & 1,06 & 0,99 & 0,90 & 0,99 \\
\hline Typering ITA & goed & redelijk & matig & matig & goed & goed & goed \\
\hline Typering loopbaan (euro) ${ }^{* *}$ & slecht & zeer goed & matig & redelijk & redelijk & goed & - \\
\hline \multicolumn{8}{|l|}{ Actuele indicatoren } \\
\hline Bruto uurloon (euro) & 13,7 & 17,3 & 17,7 & 19,2 & 25,1 & 34,7 & - \\
\hline Werkenden & 45.500 & 13.500 & 36.500 & 42.000 & 42.000 & 16.000 & 197.000 \\
\hline Werkzaamheid (\%) & 48 & 67 & 68 & 82 & 79 & 87 & 67 \\
\hline Werkloosheid (\%) & 5 & 6 & 5 & 4 & 3 & 2 & 4 \\
\hline Vast werk (\%) & 65 & 59 & 84 & 86 & 90 & 92 & 80 \\
\hline Voltijds (\%) & 43 & 34 & 53 & 54 & 52 & 57 & 50 \\
\hline Wekelijkse arbeidsduur (uur) & 26,2 & 24,0 & 31,7 & 32,8 & 32,8 & 33,7 & 30,5 \\
\hline Leeftijd werkenden (jaar) & 40,3 & 33,6 & 42,6 & 41,1 & 40,7 & 43,4 & 40,8 \\
\hline Student/scholier (\%) & 22 & 37 & 2 & 4 & 2 & 0 & 9 \\
\hline
\end{tabular}

"Prognoses als gemiddeld jaarlijks percentage van de werkzame beroepsbevolking in 2016; actuele indicatoren als percentage van de werkzame, totale of potentiële beroepsbevolking 2015-2016 (zie Tekstbox 1), tenzij anders aangegeven

** Lonen voor Nederland in 2016

Figuur 1

Sectorspecialisatie Regio Zwolle ten opzichte van Nederland (2015-2016)

Landbouw, bosbouw en visserii Voedings- en genotmiddelenindustrie Chemische industrie Metaalindustrie Overige industrie Energie Bouwnijverheid

Detailhandel

Groothandel Vervoer en opslag Horeca

Informatie en communicatie Financiële dienstverlening en onroerend goed Special istische zakelijke dienstverlening Verhuur en overige zakelijke dienstverlening Openbaar bestuur en overheidsdiensten Onderwijs Zorg

Welzijn

Cultuur sport en recreatie Overige dienstverlening, huishoudens en

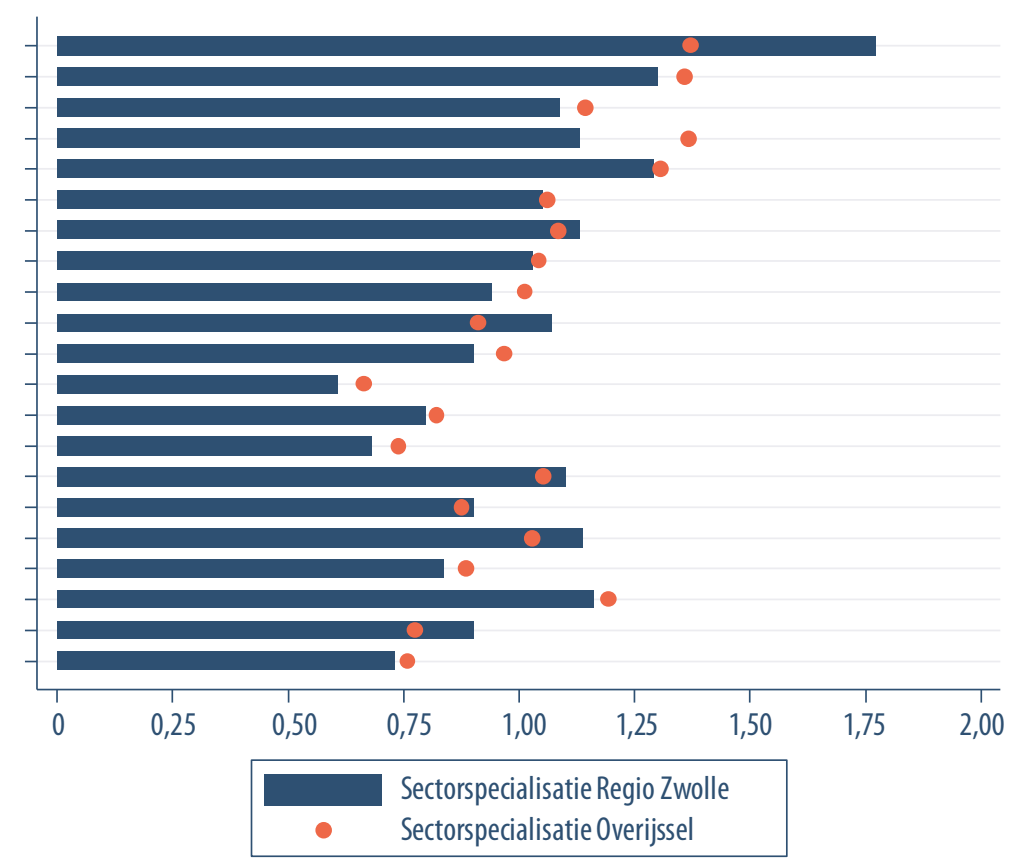
extraterritoriale organisaties 
Tekstbox 1 Definities kernbegrippen

\begin{tabular}{|c|c|}
\hline Variabele & Definitie \\
\hline Uitbreidingsvraag & $\begin{array}{l}\text { Vraag naar nieuwe arbeidskrachten die ontstaat door de groei van de werkgelegenheid. Als er sprake is van een werkgelegenheidsdaling, is de } \\
\text { uitbreidingsvraag negatief. }\end{array}$ \\
\hline Vervangingsvraag & $\begin{array}{l}\text { Vervangingsvraag is de vraag naar nieuwe arbeidskrachten die ontstaat door bijvoorbeeld pensionering, (tijdelijke) uittreding vanwege zorgtaken, } \\
\text { arbeidsongeschiktheid, beroepsmobiliteit of doorstroom naar een andere opleiding. }\end{array}$ \\
\hline Arbeidsmarktuitstroom & De som van de vervangingsvraag en de negatieve uitbreidingsvraag. \\
\hline Arbeidsmarktinstroom & $\begin{array}{l}\text { De arbeidsmarktinstroom is het verwachte aanbod van nieuwe arbeidskrachten op de arbeidsmarkt. Deze is gebaseerd op de verwachte uitstroom van } \\
\text { schoolverlaters uit het initiële dag-, deeltijd-, niet-reguliere voltijdonderwijs en de beroepsgerichte volwasseneneducatie. Het weergegeven aanbod in de } \\
\text { figuren } 2 \text { en } 3 \text { is de instroom. Gecorrigeerd voor mobiliteitsstromen tussen arbeidsmarktregio's. }\end{array}$ \\
\hline Baanopeningen & $\begin{array}{l}\text { Baanopeningen zijn de totale vraag naar nieuwkomers op de arbeidsmarkt, zoals deze is bepaald door de werkgelegenheidsgroei (positieve uitbreidingsvraag) } \\
\text { en de vervangingsvraag. In de figuren } 2 \text { en } 3 \text { is dit de vraag naar arbeid. }\end{array}$ \\
\hline ITA & $\begin{array}{l}\text { Indicator Toekomstige Arbeidsmarktperspectief (ITA) van schoolverlaters en werkzoekenden. Deze indicator is gelijk aan een deling van het verwachte aanbod } \\
\text { door de verwachte vraag tot 2022. Naarmate de waarde van de ITA hoger ligt, is er sprake van een slechter arbeidsmarktperspectief. Een waarde tussen 1,01 en } \\
1,05 \text { duidt op een evenwichtssituatie. }\end{array}$ \\
\hline Typering ITA & $\begin{array}{l}\text { Een kwalitatieve beschrijving van de ITA. ITA } \leq 0,85 \text { wordt als "zeer goed" getypeerd, ITA }>0,85 \text { en } \leq 1,00 \text { als "goed", ITA }>1,00 \text { en } \leq 1,05 \text { als "redelijk", ITA > } \\
1,05 \text { en } \leq 1,15 \text { als "matig" en ITA }>1,15 \text { als "slecht". }\end{array}$ \\
\hline Typering loopbaan & $\begin{array}{l}\text { Het bruto uurloon van werkenden in de leeftijdsgroep 40-49 jaar ten opzichte van het bruto uurloon van werkenden in de leeftijdsgroep } 20-29 \text { jaar. Gemiddelde } \\
\text { ciffers voor Nederland in } 2016 .\end{array}$ \\
\hline Bruto uurloon & $\begin{array}{l}\text { Gemiddeld bruto uurloon van werknemers in euro's. Enquête Beroepsbevolking (EBB) gekoppeld aan het Sociaal Statistisch Bestand (SSB) van het jaar } 2016 . \\
\text { Gemiddelde ciifers voor Nederland in } 2016 .\end{array}$ \\
\hline Werkenden & Minimaal 1 uur werkzaam per week en in de leeftijd 15-74. Cijfers op basis van de Enquête Beroepsbevolking van het CBS. \\
\hline Werkzaamheid & Het percentage werkzaam is de werkzame beroepsbevolking als percentage van de potentiële beroepsbevolking (iedereen ouder dan 15 en jonger dan 75 jaar). \\
\hline Werkloosheid & $\begin{array}{l}\text { Percentage personen die geen betaald werk hebben, wel recent hebben gezocht en daarvoor direct beschikbaar zijn als percentage van de totale } \\
\text { beroepsbevolking (werkzaam en werkloos). }\end{array}$ \\
\hline Vast werk & Personen met een vast dienstverband. Percentage op basis van werknemers in de werkzame beroepsbevolking. \\
\hline Voltijds & Voltijdarbeid betreft personen die minstens 35 uur per week werkzaam zijn. Percentage op basis van de werkzame beroepsbevolking. \\
\hline Leeftijd & Gemiddelde leeftijd. \\
\hline Uren & Gemiddeld aantal uren werk per week. \\
\hline Student/scholier & Percentage van de werkenden met maatschappelijke positie student/scholier. \\
\hline Sectorspecialisatie & $\begin{array}{l}\text { De verhouding tussen het aandeel van het aantal werkenden in een sector in een bepaalde regio ten opzichte van het aandeel van die sector in Nederland. Een } \\
\text { sectorspecialisatiecoêfficieint groter dan } 1 \text { impliceert dat het aandeel werkenden in de desbetreffende sector in de regio groter is dan in Nederland als geheel. }\end{array}$ \\
\hline Opleidingsspecialisatie & $\begin{array}{l}\text { De ratio van het aandeel personen met een bepaalde opleidingscategorie die wonen in een bepaalde regio ten opzichte van het aandeel van die } \\
\text { opleidingscategorie in het Nederlandse totaal. Indien de specialisatiecoëfficiënt voor een opleidingscategorie groter is dan 1, betekent dit dat de regio in } \\
\text { verhouding tot Nederland een groter aandeel van mensen met deze opleiding kent. }\end{array}$ \\
\hline
\end{tabular}


factsheet $8 \mathrm{C}$ ) is deze het meest uitgesproken in de voedingsen genotmiddelenindustrie en de overige industrie. Verder kennen de welzijnssector en de onderwijssector een relatief groot aandeel werkenden in deze regio. Voorbeelden van sectoren met een kleiner werkgelegenheidsaandeel in verhouding tot Nederland, zijn informatie en communicatie en specialistische zakelijke dienstverlening.

\section{Perspectieven naar opleidingscategorie}

De vraag- en aanbodprognoses per opleidingscategorie voor de periode 2017-2022 zijn weergeven in Figuren 2 en 3 . Behalve basisonderwijs/vmbo en hbo 4 techniek, hebben alle schoolverlaters binnen het lager en middelbaar onderwijs een ITA groter dan I. De slechtste perspectieven worden daarbij veruit verwacht voor schoolverlaters van mbo $2 / 3$ groen. De situatie is gunstiger in het hoger onderwijs. Daar vallen in eerste instantie de zeer goede perspectieven voor gediplomeerden van wo techniek op, die een gevolg zijn van een bijzonder grote geschatte vraag. Aangezien bovendien afgestudeerden van hbo techniek en mbo 4 techniek respectievelijk goede en zeer goede ITA-typeringen hebben, betekent dit dat Regio Zwolle gemiddeld de beste arbeidsmarktperspectieven kent voor technisch opgeleiden in Overijssel. Die vaststelling suggereert bovendien dat de industriële sectoren in Regio Zwolle moeilijkheden kunnen ondervinden bij het invullen van technische vacatures.

Hetzelfde geldt naar verwachting ook binnen de sector landbouw, bosbouw en visserij voor vacatures die bestemd zijn voor hbo en wo landbouw en natuur. Voor de schoolverlaters van mbo $2 / 3$ groen en mbo 4 groen worden dergelijke fricties echter niet voorzien vanwege een ITA die groter is dan I. Een discrepantie tussen de arbeidsmarktperspectieven voor lager/middelbaar en hoger onderwijs is er ook bij de zorggerichte opleidingen, met matige vooruitzichten voor $\mathrm{mb}$ 2/3- en mbo 4 zorg en welzijn en goede vooruitzichten voor hbo gezondheidszorg en wo medisch.

\section{Relatie arbeidsmarktperspectieven en specialisatie naar opleiding}

Zoals blijkt uit Figuur 4 verloopt ook voor Regio Zwolle de relatie tussen de ITA en de specialisatie per opleidingscategorie vrij positief lineair. De meeste hogere opleidingen zijn proportioneel minder vertegenwoordigd dan in Nederland, en degenen die minder voorkomen hebben bovendien doorgaans en gunstige ITA. Die combinatie geldt in het bijzonder voor de opleidingscategorieën wo landbouw en natuur en wo techniek. Tussen mbo $2 / 3$ en mbo 4 groen bestaat een aanzienlijke discrepantie tussen hun relatieve voorkomen ten opzichte van Nederland, waarbij het aandeel van mbo 4 groen meer dan twee maal zo groot is als het Nederlandse. Het grotere relatieve voorkomen van mbo 4 groen verhindert evenwel niet dat schoolverlaters van deze opleidingscategorie duidelijk betere arbeidsmarktperspectieven hebben dan schoolverlaters van mbo $2 / 3$ groen. Ten slotte komt ook hbo gedrag en maatschappij beduidend vaker voor in Regio Zwolle en hebben schoolverlaters van deze categorie tegelijkertijd een nadelige ITA, terwijl het omgekeerde geldt voor wo gedrag en maatschappij.

\section{Conclusie}

In vergelijking met de andere twee arbeidsmarktregio's heeft Regio Zwolle tot 2022 voor alle opleidingsniveaus de beste perspectieven voor schoolverlaters en werkzoekenden, met een vraagoverschot en goede arbeidsmarktperspectieven voor hoogopgeleiden. Ook de werkloosheid is lager dan in Overijssel als geheel. Hoogopgeleiden kennen net als in Overijssel wel duidelijk betere vooruitzichten dan middelbaar geschoolden. Voor deze laatsten worden namelijk ook in Regio Zwolle slechts matige arbeidsmarktperspectieven verwacht, hoewel de ITA's voor mbo $2 / 3$ en mbo 4 wel nipt gunstiger zijn dan in de andere twee arbeidsmarktregio's. De goede vooruitzichten voor schoolverlaters en werkzoekenden van het hbo en wo hebben dan weer betrekking op een relatief kleine groep mensen, aangezien hoogopgeleiden in Regio Zwolle proportioneel minder vaak voorkomen dan in Nederland als geheel.

Ten opzichte van Nederland kent Regio Zwolle een relatief grote werkgelegenheid in de industriesectoren, de onderwijssector, de welzijnssector en de landbouw, bosbouw en visserij. Gegeven de gunstige perspectieven voor technisch geschoolden zullen de industriesectoren daarbij de komende zes jaar naar verwachting te maken krijgen met knelpunten bij het invullen van technische vacatures op mbo 4-, hbo- en wo-niveau. Met betrekking tot de welzijnssector wordt daarentegen een aanbodoverschot verwacht van schoolverlaters en werkzoekenden van mbo 2/3- en mbo 4 zorg en welzijn. 
6 Arbeidsmarktprognoses Regio Zwolle 2017-2022

Figuur 2

Vraag en aanbod voor opleidingscategorieën lager/middelbaar (beroeps)onderwijs, Regio Zwolle (2017-2022)

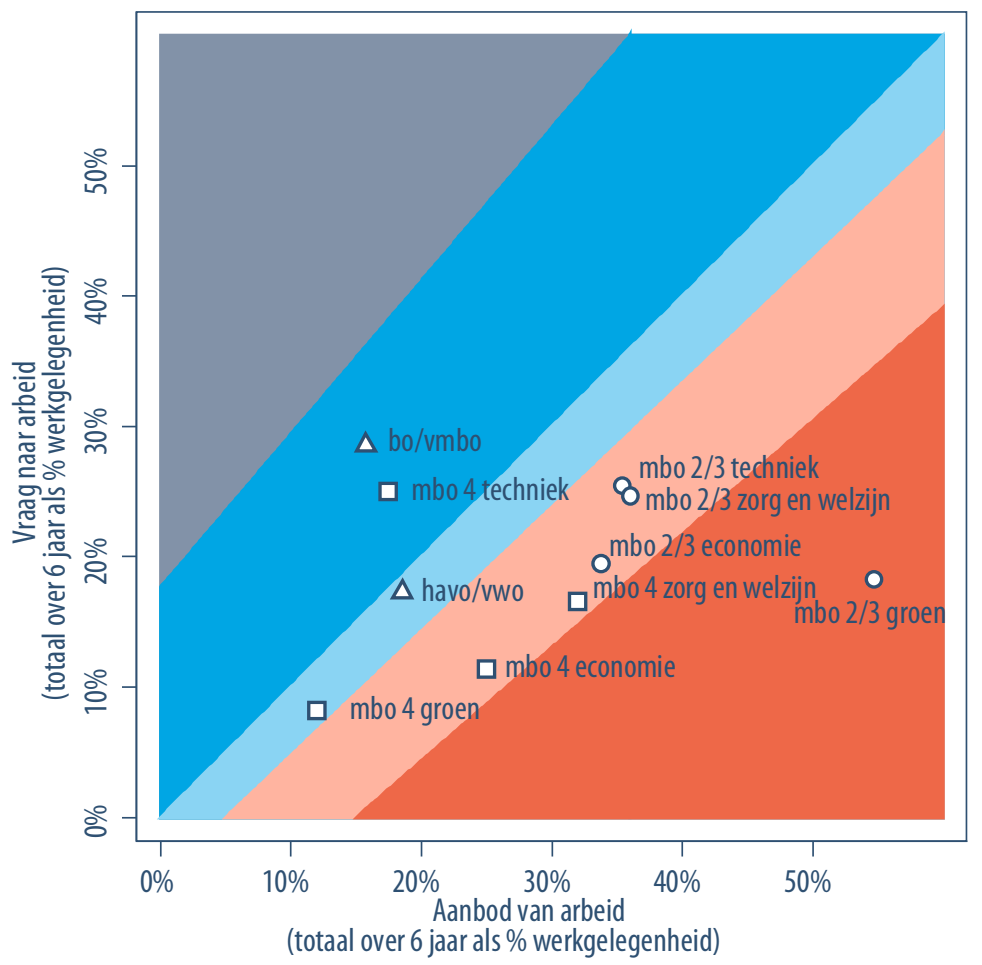

\begin{tabular}{|c|c|}
\hline & ITA-typering zeer goed \\
\hline & ITA-typering goed \\
\hline & ITA-typering redelijk \\
\hline & ITA-typering matig \\
\hline & ITA-typering slecht \\
\hline$\Delta$ & $\begin{array}{l}\text { po/vmbo en } \\
\text { havo/vwo }\end{array}$ \\
\hline 0 & mbo $2 / 3$ \\
\hline$\square$ & mbo 4 \\
\hline
\end{tabular}

Figuur 3

Vraag en aanbod voor opleidingscategorieën hoger onderwijs, Regio Zwolle (2017-2022)

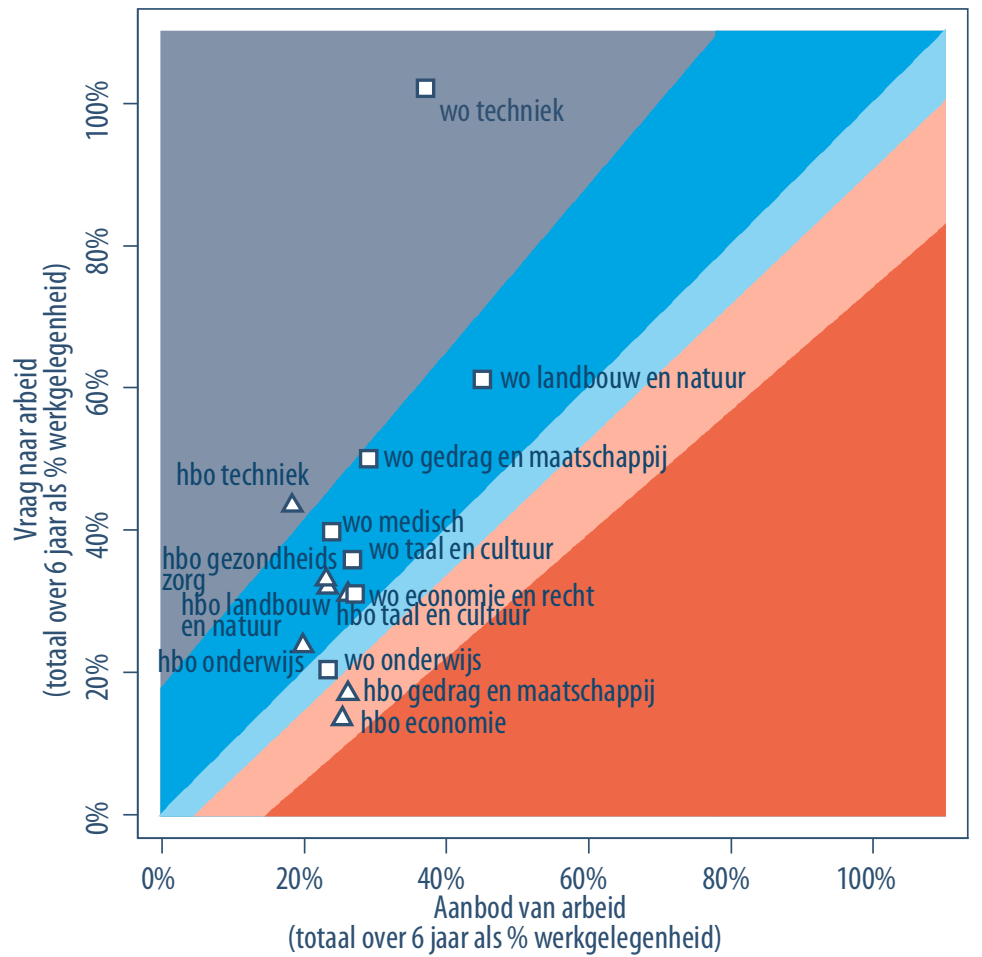




\section{Figuur 4}

Arbeidsmarktperspectieven (ITA) versus specialisatie naar opleidingscategorie, Regio Zwolle

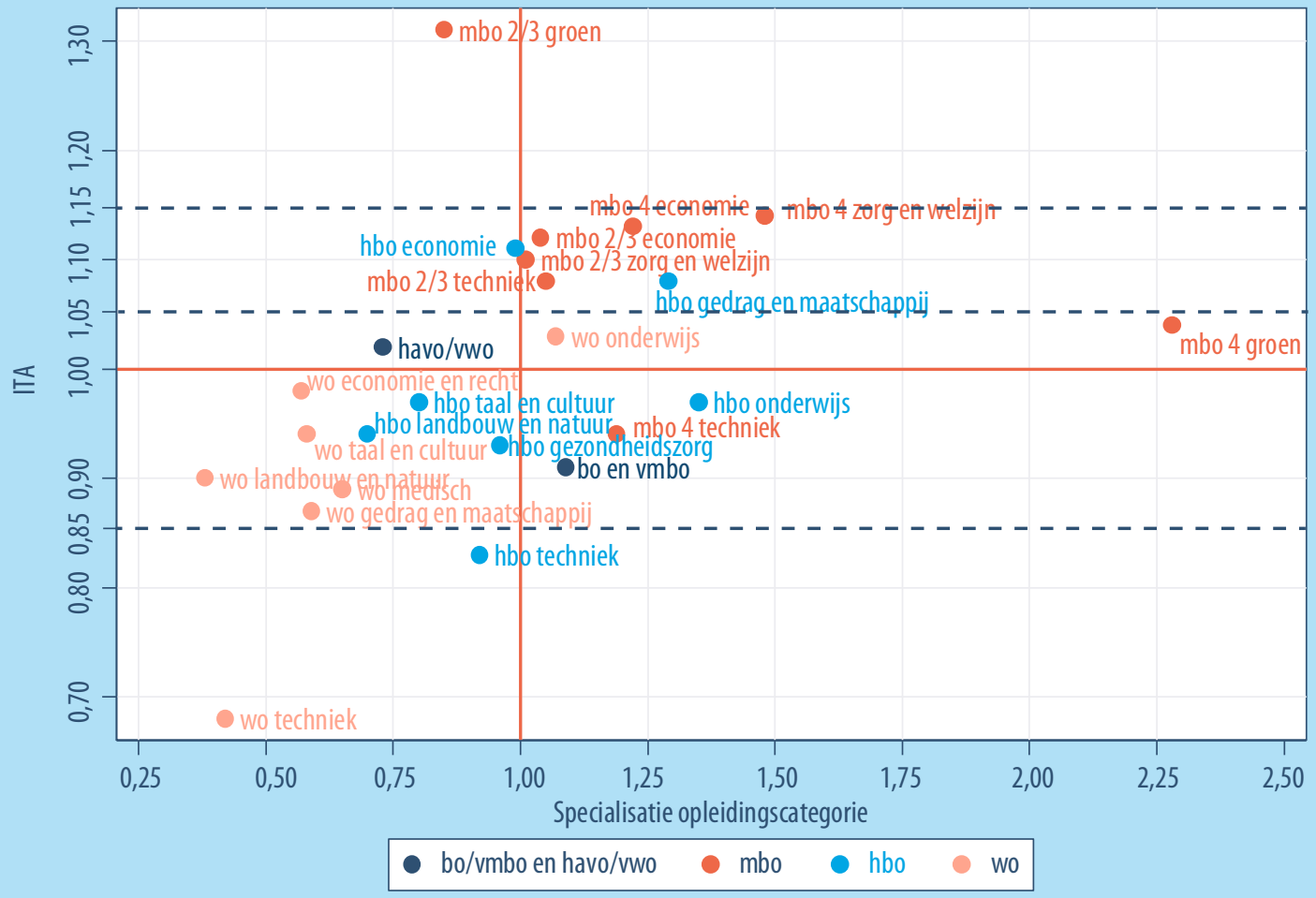




\section{Colofon}

( ) Researchcentrum voor Onderwijs en Arbeidsmarkt Niets uit deze uitgave mag op enige manier worden verveelvoudigd zonder voorafgaande schriftelijke toestemming van de directeur van het ROA.

Researchcentrum voor Onderwijs en Arbeidsmarkt

Maastricht University

School of Business and Economics

secretary-roa-sbe@maastrichtuniversity.nl

www.roa.n

\section{Vormgeving}

ROA secretariaat, Maastricht

maart 2018 